\title{
ANALISIS MASALAH PENGEMBANGAN PERBANKAN SYARIAH DI INDONESIA: APLIKASI METODE ANALYTIC NETWORK PROCESS
}

\author{
Aam Slamet Rusydiana \\ SMART Consulting \\ aamsmart@gmail.com
}

\begin{abstract}
.
This study would try to address the problems that faced by Islamic banking institutions in Indonesia. The results showed that the problems that arise in the development of Islamic banks in Indonesia consists of four important aspects, namely: human, technical, legal/structural aspect, and market/communal aspect. Decomposition of problem as a whole gains the priorities: 1) There is not enough of Islamic banks capital yet; 2) Lack of understanding of Islamic bank practitioners; 3) Lack of government support; 4) the trust and public interest to Islamic banks tend to be low. While the priority of policy strategies that are considered able to resolve the problems of Islamic banking industry in Indonesia consists of: 1) strengthen the capital and business scale and improve the efficiency level; 2) improve the quantity and quality of human resources, and also information systems and technologies; Furthermore, 3) improve the structure of Islamic bank funds and harmonization of regulation and supervision.
\end{abstract}

Keywords: Islamic banks; analytical network process; strategy

\begin{abstract}
Abstrak.
Studi ini akan mencoba menjawab masalah-masalah yang dihadapi oleh institusi perbankan syariah di Indonesia. Hasil penelitan menunjukkan bahwa permasalahan yang muncul dalam pengembangan bank syariah di Indonesia terdiri dari 4 aspek penting yaitu: SDM, teknikal, aspek legal/struktural, dan asapek pasar/komunal. Penguraian aspek masalah secara keseluruhan menghasilkan urutan prioritas: 1) Belum memadainya permodalan bank syariah; 2) Lemahnya pemahaman praktisi bank syariah; 3) Kurangnya dukungan pemerintah dan 4) Trust \& minat masyarakat terhadap bank syariah cenderung rendah. Sedangkan prioritas strategi kebijakan yang dianggap mampu menyelesaikan permasalahan industri perbankan syariah di Indonesia terdiri dari: 1) memperkuat permodalan dan skala usaha serta memperbaiki tingkat efisiensi; 2) memperbaiki kuantitas dan kualitas sumber daya manusia bank syariah, berikut juga sistim informasi dan teknologi; 3) perbaikan struktur dana bank syariah dan harmonisasi pengaturan dan pengawasan.
\end{abstract}

Kata Kunci: perbankan syariah; analytic network process; strategi

Diterima: 18 Juni 2016; Direvisi: 28 Agustus 2016; Disetujui: 19 September 2016 


\section{PENDAHULUAN}

Saat ini, menurut data dari Otoritas Jasa Keuangan (OJK) per Bulan Desember 2015, berdasarkan statistik perbankan syariah, jumlah perbankan syariah telah mencapai 12 Bank Umum Syariah, 22 Unit Usaha Syariah dan 163 Bank Pembiayaan Rakyat Syariah dengan total jaringan kantor sebanyak 2,301 kantor di seluruh Indonesia. Dalam perkembangan terakhir, industri perbankan syariah ternyata mengalami penurunan performa dibanding perbankan konvensional. Misalnya, tercermin dari non performaing financing yang relatif tinggi. Ataupun pengukuran efisiensi yang lebih rendah dibanding industri perbankan konvensional. Eksistensi bank syariah di Indonesia belum didukung oleh faktor-faktor pendukung yang memungkinkan perbankan syariah untuk terus berkembang dan berjalan dengan baik.

Ada beberapa faktor yang menjadi penghambat berkembangnya industri perbankan syariah di Indonesia, antara lain: belum memadainya sumber daya manusia yang terdidik dan profesional, menyangkut manajemen sumber daya manusia dan pengembangan budaya serta jiwa wirausaha (entrepreneurship) bangsa kita yang masih lemah, permodalan (dana) yang relatif kecil dan terbatas, adanya ambivalensi antara konsep syariah pengelolaan bank syariah dengan operasionalisasi di lapangan, tingkat kepercayaan yang masih rendah dari umat Islam dan secara akademik belum terumuskan dengan sempurna untuk mengembangkan lembaga keuangan syariah dengan cara sistematis dan proporsional. Kompleksitas persoalan tersebut menimbulkan dampak terhadap kepercayaan masyarakat tentang keberadaan bank syariah di antara lembaga keuangan konvensional.

Eksistensi perbankan syariah, jelas memiliki arti penting bagi pembangunan ekonomi berwawasan syariah terutama dalam memberikan solusi bagi pemberdayaan usaha kecil dan menengah serta menjadi inti kekuatan ekonomi yang berbasis kerakyatan dan sekaligus menjadi penyangga utama sistem perekonomian nasional. Hal ini menunjukkan peranan bank syariah sangat berarti bagi masyarakat karena ia merupakan suatu lembaga intermediasi yang mampu memecahkan permasalahan fundamental yang dihadapi oleh pengusaha kecil dan 
menengah khususnya di bidang permodalan. Bank syariah tidak hanya befungsi dalam penyaluran modal tetapi juga berfungsi untuk menangani kegiatan sosial.

Siswanto (2009) mencoba menganalisa kelemahan dan kelebihan dari lembaga BMT dengan menggunakan teknik SWOT, Di antara kelemahan LKS adalah terdiri dari a) faktor eksternal (tingkat kompetisi dengan pesaing, koloborasi atau kerja sama dengan lembaga keuangan, kebijakan pemerintah serta faktor eksternal yang lain seperti LSM). b). faktor internal (produk program pembiayaan dan tabungan, kompetensi manajemen serta pengelolaan keuangan). Solusi yang ditawarkan terkait dengan permasalahan tersebut, a) harus memfokuskan diri pada visi dan penciptaan image yang positif bagi masyarakat, prospek bisnis, kapasitas manajemen, sistem teknologi, operasional dan resiko.

Susilo (2008) mencoba merumuskan strategi yang dapat dilakukan oleh BPRS dalam pengembangan Usaha Kredit bagi UMK. Hasil penelitian menunjukkan bahwa faktor utama yang menjadi kekuatan BPRS PT Amanah Ummah adalah posisi dan strategi yaitu dekat dengan nasabah, sedangkan yang menjadi kelemahannya adalah terbatasnya kualitas sumber daya insani, yang menjadi peluang adalah potensi pangsa pasar umat islam yang terletak di lingkungan pesantren, sedangkan yang menjadi ancaman bagi BPRS adalah banyaknya pesaing dalam usaha kecil menengah. Dari penelitian tersebut menjelaskan bahwa lokasi strategis, pangsa pasar, kualitas sumber daya insani dan jumlah para pesaing menjadi faktor pengembangan BPRS. Hal ini dapat juga kita kaitkan dengan lembaga bank syariah secara umum yang merupakan bagian dari lembaga keuangan syariah. Oleh karena itu, dalam pengembangan bank syariah keempat hal tersebut harus diperhatikan dan ditangani dengan baik.

Oleh karena itu, berdasarkan latar belakang yang telah diungkapkan di atas, maka rumusan masalah yang diangkat dalam penelitian ini adalah: apa sajakah masalah-masalah yang dihadapi oleh institusi perbankan syariah di Indonesia terutama 1-2 tahun terakhir? Apa saja solusi yang tepat? Bagaimana strategi yang harus diterapkan dalam kerangka strategis jangka panjang? Dengan pendekatan metode Analytic Network Process (ANP), beberapa pertanyaan tersebut akan coba dijawab dan dicarikan solusinya.

\section{METODE}


Dalam penelitian ini, data yang digunakan merupakan data primer yang didapat dari hasil wawancara (indepth interview) dengan dengan pakar dan praktisi, yang memiliki pemahaman tentang permasalahan yang dibahas. Dilanjutkan dengan pengisian kuesioner pada pertemuan kedua dengan responden. Pemilihan responden pada penelitian dilakukan dengan mempertimbangkan pemahaman responden terhadap permasalahan dalam pengembangan bank syariah di Indonesia. Jumlah responden dalam penelitian ini terdiri dari tiga orang pakar dan praktisi dengan pertimbangan berkompeten. Syarat responden yang valid dalam ANP adalah bahwa mereka adalah orang-orang yang menguasai atau ahli di bidangnya. Oleh karena itu, responden yang dipilih dalam survey ini adalah para pakar/peneliti ekonomi Islam dan praktisi bank syariah.

Penelitian ini merupakan penelitian analisis kualitatif-kuantitatif dimana bertujuan untuk menangkap suatu nilai atau pandangan yang diwakili para pakar dan praktisi tentang perbankan syariah di Indonesia. Alat analisis yang digunakan adalah metode ANP. Analytic Network Process (ANP) juga merupakan teori matematis yang mampu menganalisa pengaruh dengan pendekatan asumsiasumsi untuk menyelasaikan bentuk permasalahan. Metode ini digunakan dalam bentuk penyelesaian dengan pertimbangan atas penyesuaian kompleksitas masalah secara penguraian sintesis disertai adanya skala prioritas yang menghasilkan pengaruh prioritas terbesar.

\section{HASIL DAN PEMBAHASAN}

Permasalahan dalam hal pengembangan perbankan syariah di Indonesia dapat dibagi menjadi 4 aspek yang terdiri dari aspek sumber daya manusia (SDM), Teknikal, Legal/Struktural dan aspek Pasar/Komunal. Cluster-cluster secara keseluruhan dikelompokkan menjadi cluster problem, solusi dan strategi.

\section{a. Problem Sumber Daya Manusia (SDM)}

Pertama, ;emahnya pemahaman praktisi bank syariah, baik sisi pengembangan bisnis maupun sisi syariah. Dengan kata lain belum terpenuhinya sumber daya insani yang mumpuni di bidang ekonomi syariah, sehingga dalam praktiknya perbankan syariah seringkali 
menyimpang dari prinsip syariah. Kedua, supply oriented. Praktisi hanya bisa menjelaskan apa yang mereka tahu tetapi tidak bisa menjawab apa yang ditanyakan oleh masyarakat. Ketiga, belum memadainya sumber daya manusia yang terdidik dan profesional, terutama teknis manajerial.

\section{b. Problem Technical}

Pertama, permodalan (dana) bank syariah masih belum memadai dan biaya dana yang mahal yang berdampak pada keterbatasan segmen pembiayaan. Dampaknya, secara umum bank syariah tidak se-efisien bank konvensional. Kedua, inovasi di bidang produk dan layanan, pemasaran dan pengembangan bisnis yang dimiliki bank syariah masih lemah, Ketiga, kurang memadainya fasilitas atau infrastruktur teknologi informasi (IT), padahal hal tersebut merupakan prasyarat penting keberhasilan lembaga keuangan.

\section{c. Problem Legal/Struktural}

Pertama, belum selarasnya visi dan kurangnya koordinasi antar pemerintah dan otoritas dalam pengembangan perbankan syariah. Kedua, pengaturan dan pengawasan yang masih belum optimal. Ketiga, Kurangnya support dan dukungan pemerintah terhadap pengembangan perbankan syariah, terutama jika dibandingkan dengan negeri Jiran.

\section{d. Problem Pasar/Komunal}

Pertama, salah satu permasalahan yang masuk dalam bagian ini adalah masalah persaingan, baik persaingan antarbank syariah sendiri maupun dengan lembaga keuangan lainnya. Kedua, masalah pada tingkat kepercayaan adalah kurangnya minat masyarakat dalam menyimpan dana di bank syariah karena rasa tidak percaya kepada bank syariah atau karena return yang rendah di banding bank konvensional. Ketiga, kurangnya pengetahuan masyarakat terhadap keberadaan bank syariah, baik dari sisi pelayanan yang diberikan, maupun pengetahuan akad yang relatif lebih "rumit".

Berdasarkan roadmap pengembangan perbankan syariah Indonesia yang dikeluarkan Otoritas Jasa Keuangan, maka terdapat beberapa elemen terkait kebijakan perbankan syariah Indonesia. Ada 7 (tujuh) arah kebijakan 
pengembangan perbankan syariah dalam rangka mencapai visi pengembangan perbankan syariah di Indonesia. Ketujuh arah kebijakan tersebut adalah: 1). Memperkuat sinergi kebijakan antara otoritas dengan pemerintah dan stakeholder lainnya, 2). Memperkuat permodalan dan skala usaha serta memperbaiki efisiensi, 3). Memperbaiki struktur dana untuk mendukung perluasan segmen pembiayaan, 4). Memperbaiki kualitas layanan dan keragaman produk, 5). Memperbaiki kuantitas dan kualitas SDM, TSI (Teknologi Sistim Informasi) serta infrastruktur lainnya, 6). Meningkatkan literasi dan preferensi masyarakat, dan 7). Memperkuat serta harmonisasi pengaturan dan pengawasan.

Berdasarkan identifikasi masalah dan arah kebijakan pengembangan perbankan syariah Indonesia di atas, selanjutnya terbentuklah jaringan struktur ANP sebagaimana pada Gambar 3. Hasil yang diperoleh memperlihatkan secara statistik konsensus dari para pakar dan praktisi terkait problem dan alternatif pengembangan bank syariah di Indonesia.
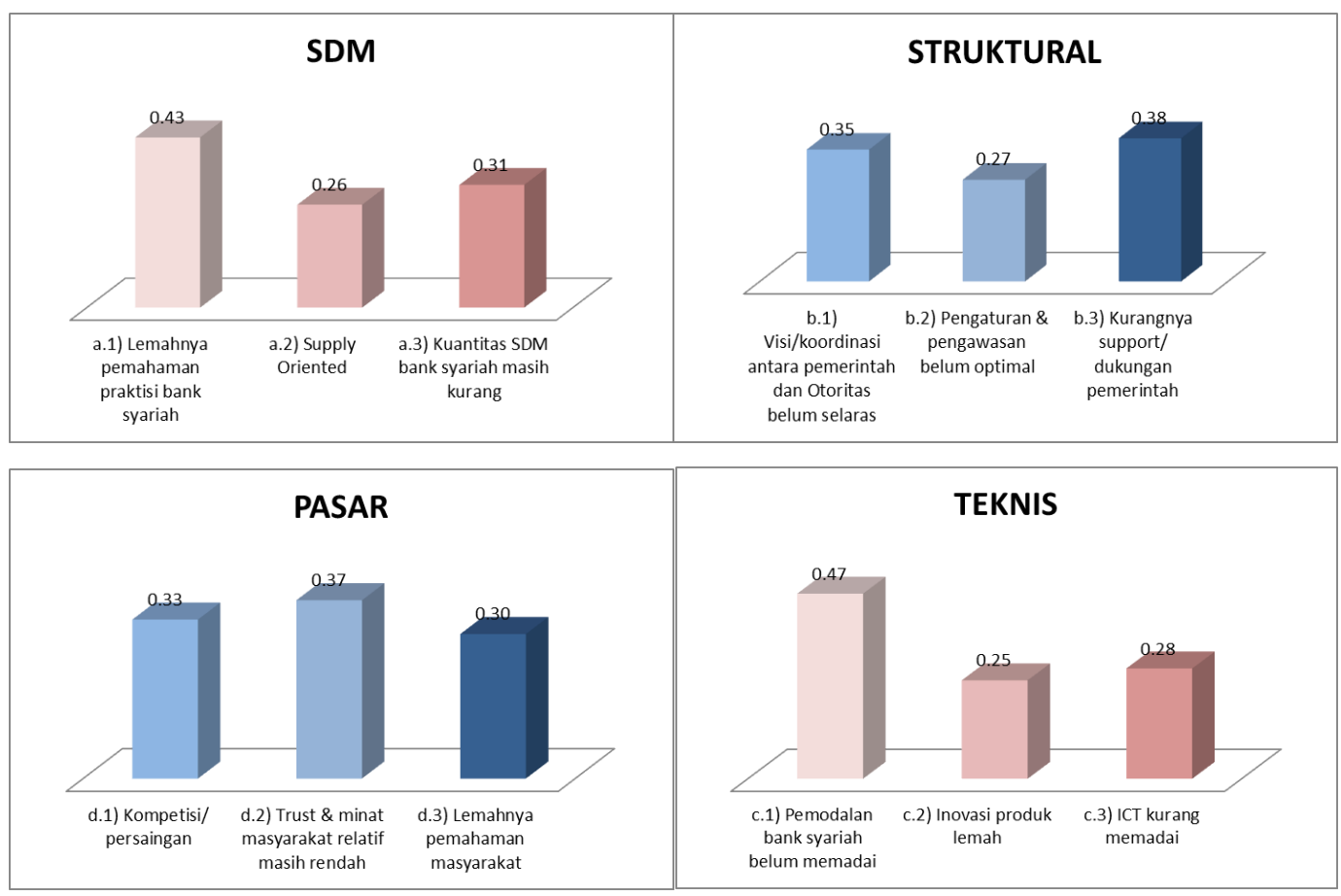

Gambar 1. Prioritas Aspek Masalah

Pada Gambar 1, untuk hasil prioritas aspek masalah menunjukkan bahwa lemahnya pemahaman praktisi bank syariah menjadi masalah utama pada sisi SDM. Pada aspek structural, kurangnya support atau dukungan pemerintah terhadap perkembangan bank syariah menjadi hal yang utama. Di sisi pasar, trust 
dan minat masyarakat yang relatif masih rendah menjadi problem utama. Sementara itu pada aspek teknis, masalah pemodalan bank syariah yang belum memadai menjadi hal terpenting. Nilai rater agreement dari keempat cluster tersebut bervariasi di antara $\mathrm{W}=0.135-0.592$. Berikut ini adalah hasil penghitungan secara lengkap terkait cluster problem berikut prioritisasinya.

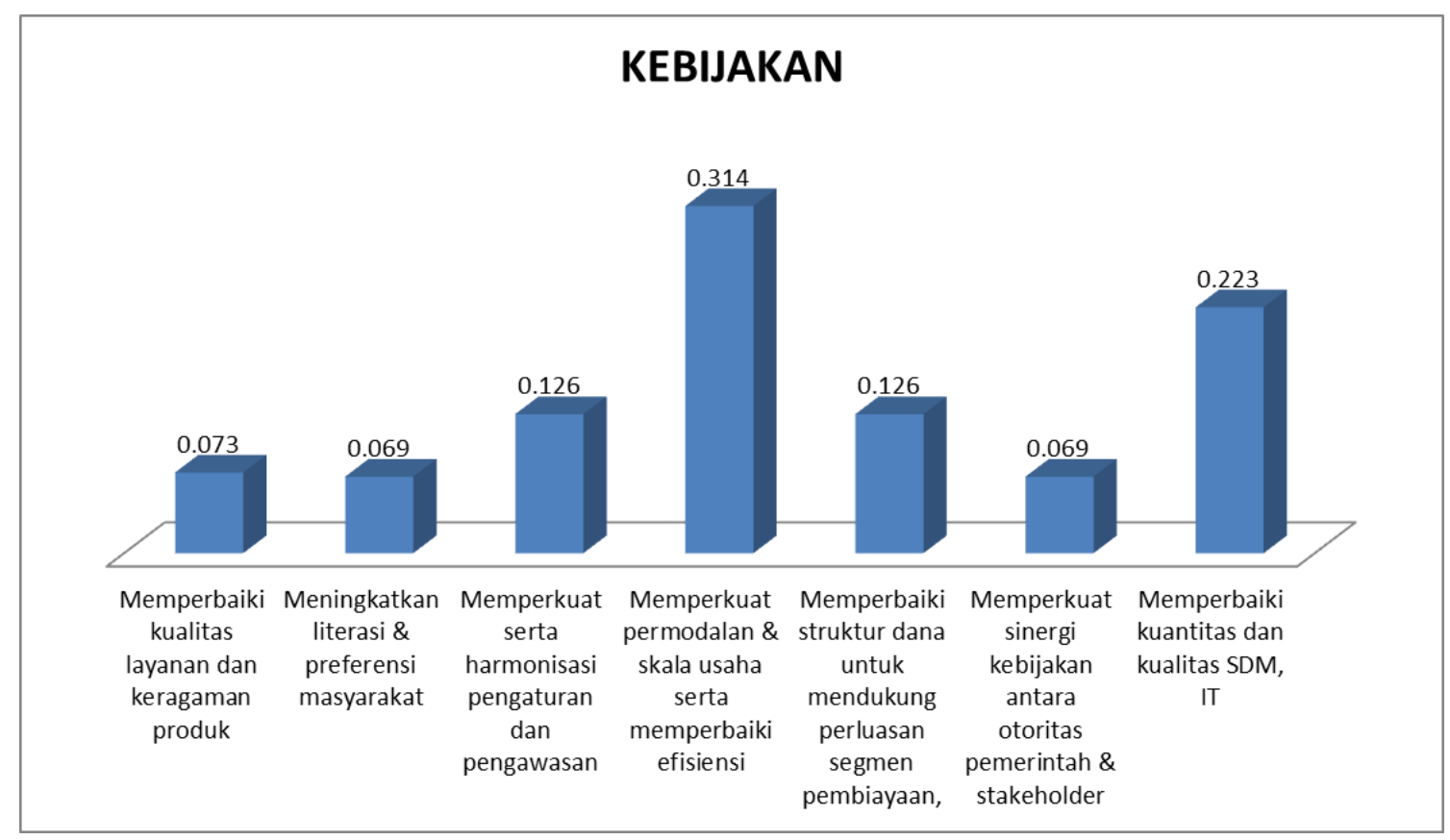

\section{Gambar 2. Prioritas Kebijakan Strategis}

Untuk aspek strategi, sebagaimana yang ditunjukan pada Gambar 2 yang terdiri atas hasil geometric mean secara keseluruhan memperlihatkan bahwa bagi pakar dan praktisi, 3 (tiga) strategi yang paling prioritas adalah: pertama, memperkuat permodalan dan skala usaha serta memperbaiki tingkat efisiensi. Strategi ini menjadi jawaban atas beberapa masalah bank syariah saat ini yaitu terkait permodalan yang masih kurang, masih mahalnya cost of production bank syariah dan hal-hal related lain. Strategi kedua sebagai prioritas adalah memperbaiki kuantitas dan kualitas sumber daya manusia bank syariah, berikut juga sistim informasi dan teknologi. Lazim diketahui bahwa masalah SDM menjadi masalah klasik bank syariah yang hingga saat ini masih menjadi PR bagi para stakeholder industri keuangan syariah. Kebijakan ini menjadi hal yang penting diimplementasikan, termasuk dengan perbaikan ICT bank syariah secara umum.

Strategi ketiga dan keempat selanjutnya adalah perbaikan struktur dana bank syariah dan harmonisasi pengaturan dan pengawasan. Dengan struktur dana 
yang lebih baik, bank syariah diharapkan akan mampu bersaing secara kompetitif dengan bank konvensional. Selain itu, regulasi dan pengawasan otoritas penting dilakukan. Memang, support dan keberpihakan pemerintah adalah salah satu kunci berkembangnya lembaga keuangan syariah di Indonesia.

\section{SIMPULAN}

Hasil penelitan menunjukkan bahwa permasalahan yang muncul dalam pengembangan bank syariah di Indonesia terdiri dari 4 aspek penting yaitu: SDM, teknikal, aspek legal/struktural, dan asapek pasar/komunal. Penguraian aspek masalah secara keseluruhan menghasilkan urutan prioritas: 1) Belum memadainya permodalan bank syariah; 2) Lemahnya pemahaman praktisi bank syariah; 3) Kurangnya dukungan pemerintah dan 4) Trust \& minat masyarakat terhadap bank syariah cenderung rendah. Sedangkan prioritas strategi kebijakan yang dianggap mampu menyelesaikan permasalahan industri perbankan syariah di Indonesia terdiri dari: 1) memperkuat permodalan dan skala usaha serta memperbaiki tingkat efisiensi; 2) memperbaiki kuantitas dan kualitas sumber daya manusia bank syariah, berikut juga sistim informasi dan teknologi; 3) perbaikan struktur dana bank syariah dan harmonisasi pengaturan dan pengawasan.

Beberapa saran dan rekomendasi yang dapat diberikan penulis antara lain: 1) Diharapkan adanya komitmen bersama dari pembuat kebijakan dalam menunjang dan mendorong upaya pengembangan industri keuangan syariah khususnya dalam hal ini bank syariah. 2) Melalui penelitian ini, diharapkan dapat memperluas kajian penelitian akademik terkait bank syariah. 3) Penelitian selanjutnya dengan pendekatan yang sama (ANP) disarankan agar dapat menambah jumlah responden dari pihak-pihak terkait yang dipandang paham akan masalah bank syariah di Indonesia. Demikian juga penggunaan model BOCR.

\section{PUSTAKA ACUAN}

Ascarya. (2011). The Persistence of Low Profit and Loss Sharing Financing in Islamic Banking: The Case of Indonesia. Review of Indonesian Economic and Business Studies. Vol. 1: 1-10. 
Ascarya \& D. Yumanita. (2010). Determinan dan Persistensi Margin Perbankan Konvensional dan Syariah di Indonesia. Working Paper Series No.WP/10/04. Pusat Pendidikan dan Studi Kebanksentralan Bank Indonesia.

Mu'allim, A. (2003).“Persepsi Masyarakat terhadap Lembaga Keuangan Syariah. Jurnal Al-Mawarid. Vol. X: 31-40.

Otoritas Jasa Keuangan. (2015). Roadmap Perbankan Syariah Indonesia 2015-2019. Departemen Perbankan Syariah OJK.

Saaty, T.L. \& L.G. Vargas. (2006). Decision Making with the Analitic Network Process. Economic, Political, Social and Technological Applications with Benefits, Opportunities, Costs and Risks. Pittsburgh: Springer.

Siswanto. (2009). Strategi Pengembangan Lembaga Keuangan Syariah Dalam Memberdayakan Usaha Kecil dan Menengah. (Tesis Tidak Dipublikasikan). Program Pascasarjana Universitas Diponegoro.

Susilo, J. (2008). Rumusan Strategi Pengembangan PT. BPRS Amanah Ummah Dengan Pendekatan Analytic Network Process. (Tesis Tidak Dipublikasikan). Program Pascasarjana Institut Pertanian Bogor.

Wibowo, H. (2006). Peranan Perbankan Syariah dalam Menggerakkan Sektor Riil. Working Paper, presented at National Seminar and Colloquium; "Perkembangan Sistem Keuangan Syariah di Indonesia Kini dan Tantangan Hari Esok", Bandung Institute of Technology, September 30 (2006). 


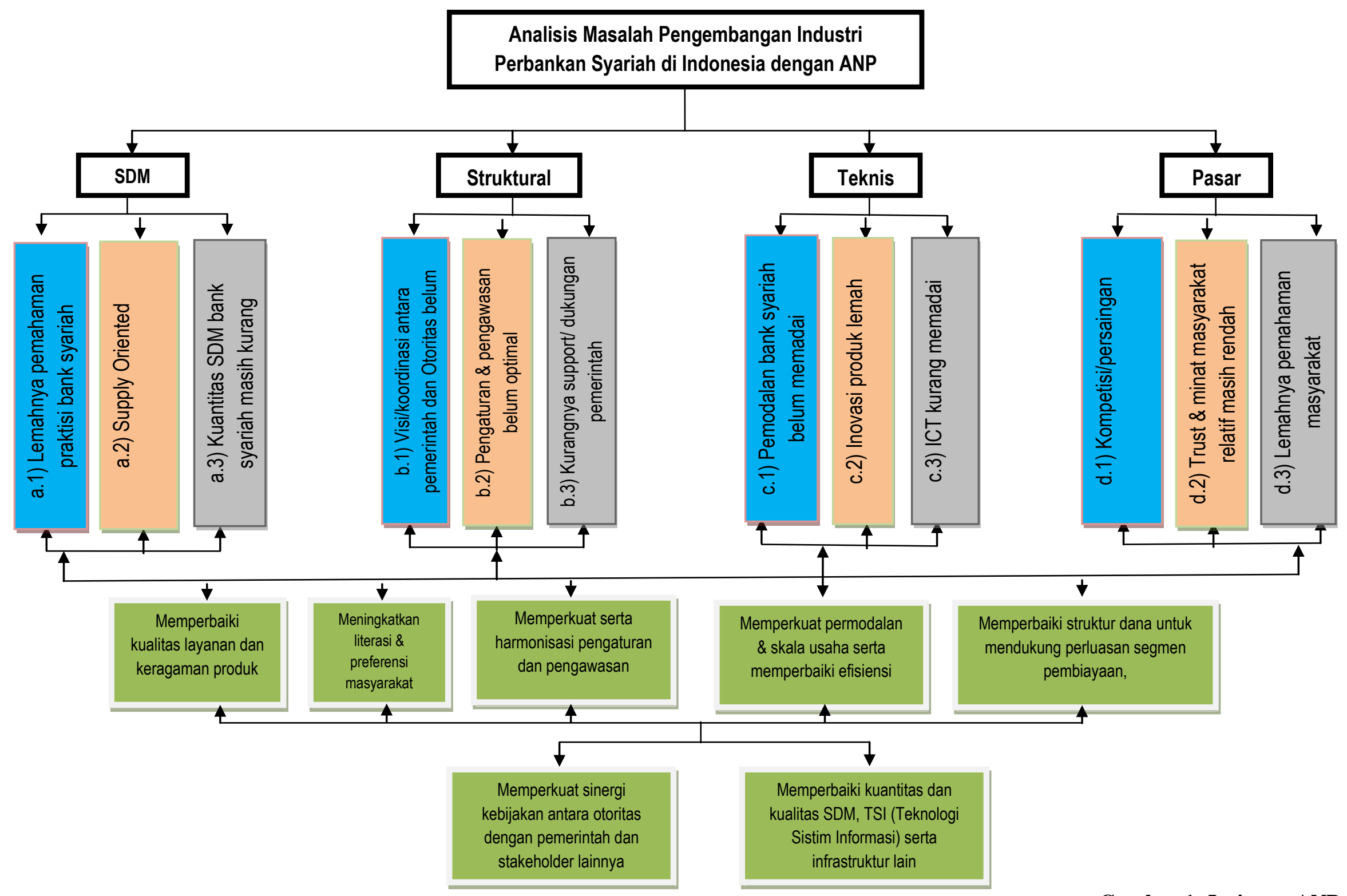

